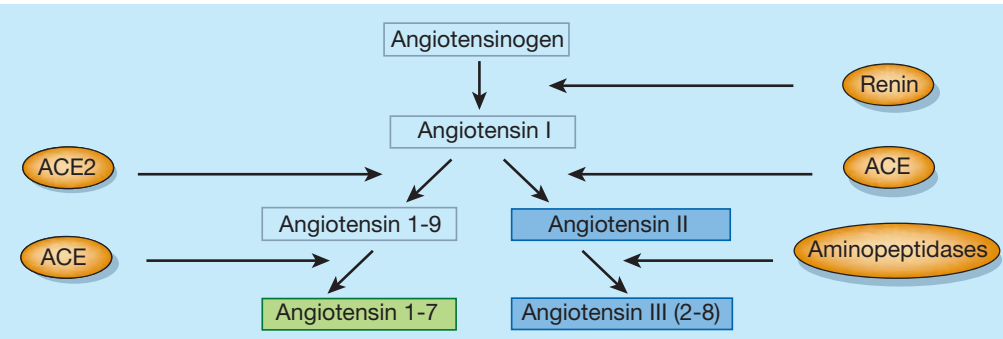

Figure 1 Angiotensin peptides. Blood-vessel constrictors are in blue; vessel dilators are in green. The enzyme renin catalyses the release of the ten-amino-acid peptide angiotensin I from the precursor protein angiotensinogen. Further catalysis by ACE produces the eight-amino-acid angiotensin II, which is a powerful vessel constrictor and results in higher blood pressure. ACE2 is thought to produce the nine-amino-acid angiotensin 1-9, which has no known effects but can be converted by ACE to angiotensin 1-7, a vessel dilator. So ACE2 has been proposed to reduce the formation of angiotensin II and to oppose the increase in blood pressure that is mediated by ACE and angiotensin II. Crackower et al. ${ }^{1}$ find that the ACE2 gene is found on a region of the rat $\mathrm{X}$ chromosome that has been implicated in high blood pressure. Yet knocking out ACE2 in mice does not raise blood pressure, but instead leads to malfunctioning heart muscle.

been suggested that ACE2 prevents the formation of the blood-vessel constrictor angiotensin II.

But what do the effects of ACE2 on angiotensin peptides mean in terms of physiology? A first hint was the finding that this enzyme is expressed solely in the heart, kidneys and testes ${ }^{2,3}$. But it is the paper by Crackower et al. ${ }^{1}$ that provides the first really compelling evidence of ACE2's biological role. First, the authors present gene-mapping studies designed to find the location of the ACE2 gene in the rat genome, specifically on the rat $\mathrm{X}$ chromosome. The reason was that studies of several rat 'models' of high blood pressure had suggested that the X chromosome contains a particular region (perhaps even a particular gene) that is important in the heritability and induction of raised blood pressure. Indeed, Crackower et al. found that the ACE2 gene maps to the same region of the $\mathrm{X}$ chromosome that has been implicated in three such models. Moreover, ACE2 protein levels were reduced in these models.

So is ACE2 involved in controlling blood pressure? To find out, Crackower et al. created 'knockout' mice lacking all ACE2 protein. Mice lacking the ACE protein have very low blood pressure ${ }^{4,5}$. Thus, one might imagine that knocking out ACE2 has the opposite effect — high blood pressure — as suggested by the rat models. In fact, the authors found that blood pressure is normal in the ACE2knockout mice. But surprisingly, and unlike the ACE-deficient mice, the ACE2-knockout animals develop abnormal (pathological) heart function as they age. Specifically, the heart muscle develops a significant defect in both the speed and the overall percentage of contraction. Unusually, though, the hearts show only mild physical changes, with virtually no increase in cardiac scarring.

Why don't the hearts of the ACE2-knockout mice function properly? Crackower et al. found that the lack of ACE2 leads to an increase in angiotensin II levels, and suggest that this may, in part, incite the pathology (through heart-specific mechanisms that apparently would not involve an effect on blood pressure). It is wise to keep an open mind, however. The increased levels of angiotensin II are significant but relatively

\title{
Zoology
}

\section{New whale from old bones}

In the mid-1970s, four dead beaked whales were washed ashore separately near San Diego, California. As announced in the latest issue of Marine Mammal Science (18, 577-608; 2002), they have now been recognized as a new species. This is something of an event — as with most large mammals, new species descriptions of cetaceans (whales, dolphins and porpoises) are not an everyday occurrence.

Initially, from an examination of the whales' skulls, James Mead tentatively identified the animals as the Southern Hemisphere species Mesoplodon hectori. At that time there were a dozen named species of beaked whale (Ziphiidae) within the genus Mesoplodon, diagnosed primarily by the size, shape and position of an enlarged pair of teeth in the adult males. An example of a beaked whale $-M$. bidens, drawn in 1843 - is shown in the picture. The enlarged teeth are used in male-male fights, not for feeding; beaked whales feed by using their tongues in a piston-like manner for sucking in prey, primarily squid.

Merel Dalebout has recently re-examined the remains of the stranded specimens, but this time by analysing DNA-sequence data. She found that data from the California animals clustered far apart from those from $M$. hectori. Dalebout, Mead and colleagues have now formally described the new species, naming it $M$. perrini after William F. Perrin, an eminent contemporary scholar of marine mammals.

The majority of the 85 species of living cetaceans were described from specimens collected during the great voyages of discovery of the eighteenth and nineteenth centuries. Most of those discovered more recently are beaked whales: for example, only 1 out of 34 species of living oceanic dolphins (Delphinidae), but 8 out of 20 beaked whale species, have been described since 1900. The reason is that, as offshore, deep-water creatures,

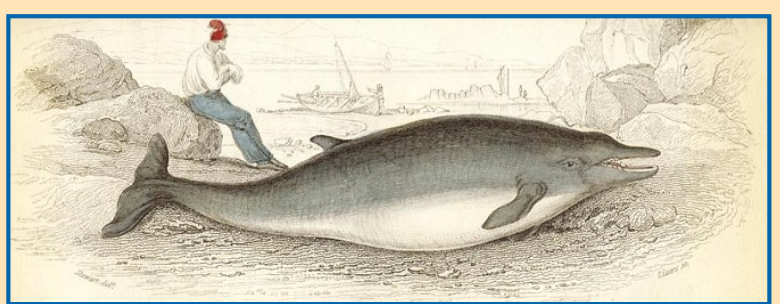

beaked whales are especially difficult to identify and study.

Dalebout and colleagues' finding is surprising because the Californian coast has long been scoured for stranded specimens, and the offshore waters have been extensively covered during surveys of marine mammal populations. Recognition of a new whale from this region highlights how little we know about biological diversity in the ocean. The discovery also exemplifies the continuing value of specimens collected decades or more ago. To resolve the identity of M. perrini with certainty, Dalebout sampled bones of the specimens that had been housed in museum collections almost a quarter of a century previously.

At $3.9 \mathrm{~m}$ long, the adult male specimen of $M$. perrini is smaller than the adult female $(4.4 \mathrm{~m})$. This is the reverse of the usual case in mammals, but is characteristic of beaked whales. The high number of calves - three of the five known specimens - is also typical for all species of Mesoplodon stranded along the Californian coast, perhaps indicating that they migrate to coastal waters for calving. John E. Heyning John E. Heyning is in the Natural History Museum of Los Angeles County, 900 Exposition Boulevard, Los Angeles, California 90007, USA. e-mail: jheyning@nhm.org 